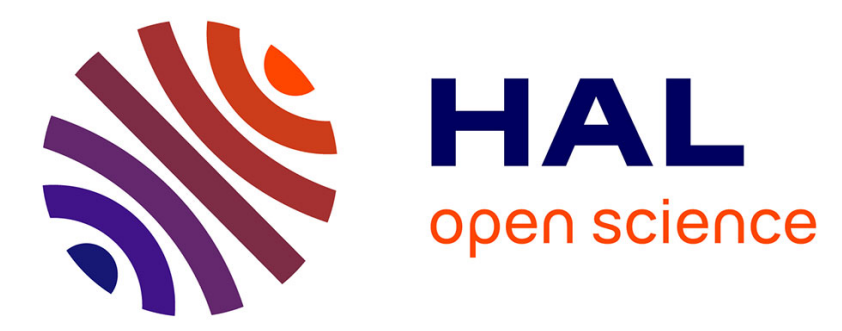

\title{
C5L2 Silencing in Human Pulp Fibroblasts Enhances Nerve Outgrowth Under Lipoteichoic Acid Stimulation
}

Fanny Chmilewsky, Imad About, Lyndon F Cooper, Seung H Chung

\section{To cite this version:}

Fanny Chmilewsky, Imad About, Lyndon F Cooper, Seung H Chung. C5L2 Silencing in Human Pulp Fibroblasts Enhances Nerve Outgrowth Under Lipoteichoic Acid Stimulation. Journal of Endodontics, 2018, 44 (9), pp.1396-1401. 10.1016/j.joen.2018.05.004 . hal-03547385

\section{HAL Id: hal-03547385 \\ https://hal.science/hal-03547385}

Submitted on 28 Jan 2022

HAL is a multi-disciplinary open access archive for the deposit and dissemination of scientific research documents, whether they are published or not. The documents may come from teaching and research institutions in France or abroad, or from public or private research centers.
L'archive ouverte pluridisciplinaire HAL, est destinée au dépôt et à la diffusion de documents scientifiques de niveau recherche, publiés ou non, émanant des établissements d'enseignement et de recherche français ou étrangers, des laboratoires publics ou privés. 


\title{
C5L2 Silencing in Human Pulp Fibroblasts Enhances Nerve Outgrowth Under Lipoteichoic Acid Stimulation
}

\author{
Fanny Chmilewsky, PhD, * Imad About, PhD, ${ }^{\dagger}$ Lyndon F. Cooper, DDS, PhD, * \\ and Seung H. Chung, DVM, PbD*
}

\begin{abstract}
Introduction: We recently reported that cariesassociated $\mathrm{C} 5 \mathrm{a}$ receptor (C5aR) expression and activation result in up-regulation of brain-derived neurotropic factor secretion by pulp fibroblasts inducing prominent neurite outgrowth toward the carious site. Our data further showed a negative regulation of this brainderived neurotropic factor secretion by $\mathrm{C} 5 \mathrm{~L} 2$, another C5aR. C5L2 was considered a nonfunctional receptor and thus has received much less attention than $\mathrm{C} 5 \mathrm{aR}$. The aim of this study was to identify the role of $\mathrm{C} 5 \mathrm{~L} 2$ in pulp fibroblast-mediated neurite outgrowth. Methods: In this study, lipoteichoic acid (LTA) was used to mimic dental caries-like inflammation. To evaluate the role of $C 5 L 2$ in pulp neurite outgrowth, human pulp fibroblasts were $\mathrm{C} 5 \mathrm{~L} 2$ small interfering RNA silenced and cocultured with human neurons in a nerve growth assay system. Results: C5L2 silencing drastically increased the neurite outgrowth toward the LTAstimulated pulp fibroblasts. The number of neurites detected was increased in the LTA-treated pulp fibroblasts. Conclusions: Our results show that $\mathrm{C} 5 \mathrm{~L} 2$ constitutes a negative regulator of the neurite outgrowth under LTA stimulation. Of the events occurring during dentin-pulp regeneration, nerve regeneration is the key factor for maintaining tooth viability after infection or injury. Our study provides a foundation for creating therapeutic tools that target pulp fibroblasts during pulp/nerve regeneration. (J Endod 2018; $\square: 1-6$ )
\end{abstract}

\section{Key Words}

$\mathrm{C} 5$ a receptor, $\mathrm{C} 5 \mathrm{~L} 2$, nerve outgrowth, pulp fibroblast
Tom ooth nerve damage is a common feature of tooth decay, and proper dental pulp innervation is required for maintaining pulp viability and integrity. Supporting this concept, pulp denervation in rat molars significantly reduced the survival and regenerating rate of exposed dental pulp tissue and caused a significant reduction in immunocompetent cell recruitment after dentin injury $(1,2)$. Further in vivo studies using rodent models have shown that pulp denervation resulted in severe morphologic tooth deformation including dentoalveolar ankyloses, reduced periodontal ligament space and Malassez epithelium, and decreased population of the recruited osteoclasts (3-5). Although the dental nerve appears to have critical importance in maintaining tooth viability, very little is known about the molecular mechanism that regulates dental pulp innervation and regeneration. Enhanced nerve regeneration may promote the morphologic and functional recovery in damaged pulp.

Complement $\mathrm{C} 5$ a release from human pulp fibroblasts has been suggested to provide a link between pulp inflammation and regeneration ability (6). We showed for the first time that human pulp fibroblasts express $\mathrm{C5a}$ receptor (C5aR) in carious tooth decay in vivo and after lipoteichoic acid (LTA) stimulation in vitro $(7,8)$. C5aR signaling results in brain-derived neurotropic factor (BDNF) secretion by pulp fibroblasts that induces prominent neurite outgrowth toward the site of carious injury (7). These first steps in response to carious injury offer new opportunities for incipient/early interventions to promote dentinal repair.

The second receptor, $\mathrm{C} 5 \mathrm{~L} 2$, shows a similar homology with $\mathrm{C} 5 \mathrm{aR}$ but produces no down-signaling pathway after binding with $\mathrm{C5a}(9,10)$. However, recent studies provided evidence that $\mathrm{C} 5 \mathrm{~L} 2$ physically interacts with $\mathrm{C} 5 \mathrm{aR}$ and negatively regulates its activity (11). In support of this observation, our previous study showed that BDNF secretion by pulp fibroblasts is oppositely regulated by these 2 receptors. Pulp fibroblast BDNF secretion was negatively regulated by C5L2 (12). Because we believe that BDNF is a key factor in controlling nerve regeneration in damaged pulp, we now hypothesize that the inhibition of C5L2 increases nerve outgrowth under LTAinduced modeled in vitro caries injury. Because $\mathrm{C5}$ a is involved in many biological processes, identifying an alternative path to modify $\mathrm{C} 5 \mathrm{a}$ signaling will provide new or complimentary avenues to investigate and translate mechanisms of dentin-pulp regeneration or repair under caries injury. The alternative approach of targeting $\mathrm{C} 5 \mathrm{~L} 2$ could provide an innovative therapeutic strategy (ie, the possibility to enhance the positive 
action of $\mathrm{C} 5 \mathrm{aR}$ in dental pulp regeneration by blocking the "inactive/ inhibitory" $\mathrm{C} 5 \mathrm{~L} 2$ receptor).

\section{Cell Gultures}

\section{Materials and Methods}

Human immature third molars, freshly extracted for orthodontics purposes, were obtained in compliance with French legislation (informed patients' consent and institutional review board approval of the protocol used at Aix-Marseille Université, Marseille, France). Human pulp fibroblasts were prepared from immature third molars at the two-thirds root formation stage by the explant outgrowth method and routinely cultured as previously described $(7,13)$.

\section{Silencing of C5L2 Expression by Small Interfering RNA}

Human pulp fibroblasts were grown in a 24 -well plate culture chamber in $500 \mu \mathrm{L}$ free-antibiotic medium up to $70 \%$ confluence, and then transient transfection with small interfering RNA (siRNA) was performed using the siRNA Reagent System (sc-45064; Santa Cruz Biotechnology, Inc, Dallas, TX) according to the manufacturer's protocol. Cells were incubated at $37^{\circ} \mathrm{C}$ in a $\mathrm{CO}_{2}$ incubator in $250 \mu \mathrm{L}$ free-antibiotic and free-serum transfection solution containing a mixture of transfection reagent and $40 \mathrm{pmol} / \mathrm{mL} /$ well C5L2 siRNA (sc-105165; Santa Cruz Biotechnology, Inc, Dallas, TX) or control siRNA, which is a nontargeting siRNA designed as a negative control (sc-37007; Santa Cruz Biotechnology, Inc). After an incubation period of 6 hours, $250 \mu \mathrm{L}$ of medium containing 2 times the normal serum and antibiotic concentration was added in each well without removing the transfection mixture. After 24 hours, the medium was aspirated and replaced with fresh normal growth medium (Dulbecco modified Eagle medium $+4.5 \mathrm{~g} / \mathrm{L}$ glucose, L-glutamine, sodium, pyruvate $+10 \%$ heat-inactivated fetal bovine serum $+100 \mu \mathrm{g} /$ $\mathrm{mL}$ streptomycin, and $100 \mathrm{U} / \mathrm{mL}$ penicillin). Assays using siRNA silenced cells were performed within 72 hours after the addition of fresh medium. Real-time polymerase chain reaction was performed to confirm the efficiency of $\mathrm{C} 5 \mathrm{~L} 2$ silencing in pulp fibroblasts.

\section{Immunofluorescence Staining}

Human pulp fibroblasts were seeded in $1 \times 10^{4}$ cells per 8-well glass culture chamber overnight before stimulation with LTA $(10 \mu \mathrm{g} /$ $\mathrm{mL}$ ). After 24 hours of treatment, cells were fixed and permeabilized as previously described (7). Then, cells were incubated for 1 hour with mouse anti-C5L2 (5 $\mu \mathrm{g} / \mathrm{mL}$; BioLegend, San Diego, CA), rabbit anti-fibroblast surface protein (FSP) $(20 \mu \mathrm{g} / \mathrm{mL}$; Abcam, Cambridge, MA), or their respective control isotypes. Finally, cells were incubated for 40 minutes with a mix of Alexa Fluor-594 antimouse immunoglobulin G (Jackson ImmunoResearch Inc, West Grove, PA) $(2 \mu \mathrm{g} / \mathrm{mL})$ and $4^{\prime}, 6$-diamidino-2-phenylindole $(1 \mu \mathrm{g} / \mathrm{mL})$. The coverslips were sealed, and photographs were taken using a Leica DMI6000 B microscope (Leica Biosystems, Wetzlar, Germany).

\section{Neurite Outgrowth Assays}

Neurite outgrowth experiments were performed using an assay kit based on the use of 24-well plates (lower chambers) equipped with cell culture inserts (upper chambers) containing a permeable membrane with 3- $\mu$ m pores (EMD Millipore, Burlington, MA). Briefly, the underside of the insert membrane surface was coated with poly-L-lysine by placing the inserts into a well containing $400 \mu \mathrm{L}$ of a $0.1 \mathrm{mg} / \mathrm{mL}$ poly-L-lysine solution (Sigma-Aldrich, St Louis, M0) for 2 hours at $37 \mathrm{C}$ (Fig. 1Aa). After coating, the inserts were placed into a new well containing human pulp fibroblasts silenced or not for $\mathrm{C} 5 \mathrm{~L} 2$ (as described previously) and treated with or without LTA $(10 \mu \mathrm{g} / \mathrm{mL})$ (Fig. 1Aa). Then, 100,000 primary human neuronal cells (Sciencell, Carlsbad, CA) were seeded onto the top of the membrane (Fig. 1Aa). The system was incubated for 48 hours at $37 \mathrm{C}$ to allow neurites to extend to the underside of the membrane. After 48 hours, the insert's membranes were fixed for 20 minutes in cold methanol and then placed into $400 \mu \mathrm{L}$ Neurite Stain Solution (EMD Millipore) for 30 minutes at room temperature (Fig. 1 $A b$ ). Finally, the neuron cell bodies on the upper side of the insert membranes were wiped off using a cotton bud (Fig. 1Ab). For each experiment, the total neurite length detected on
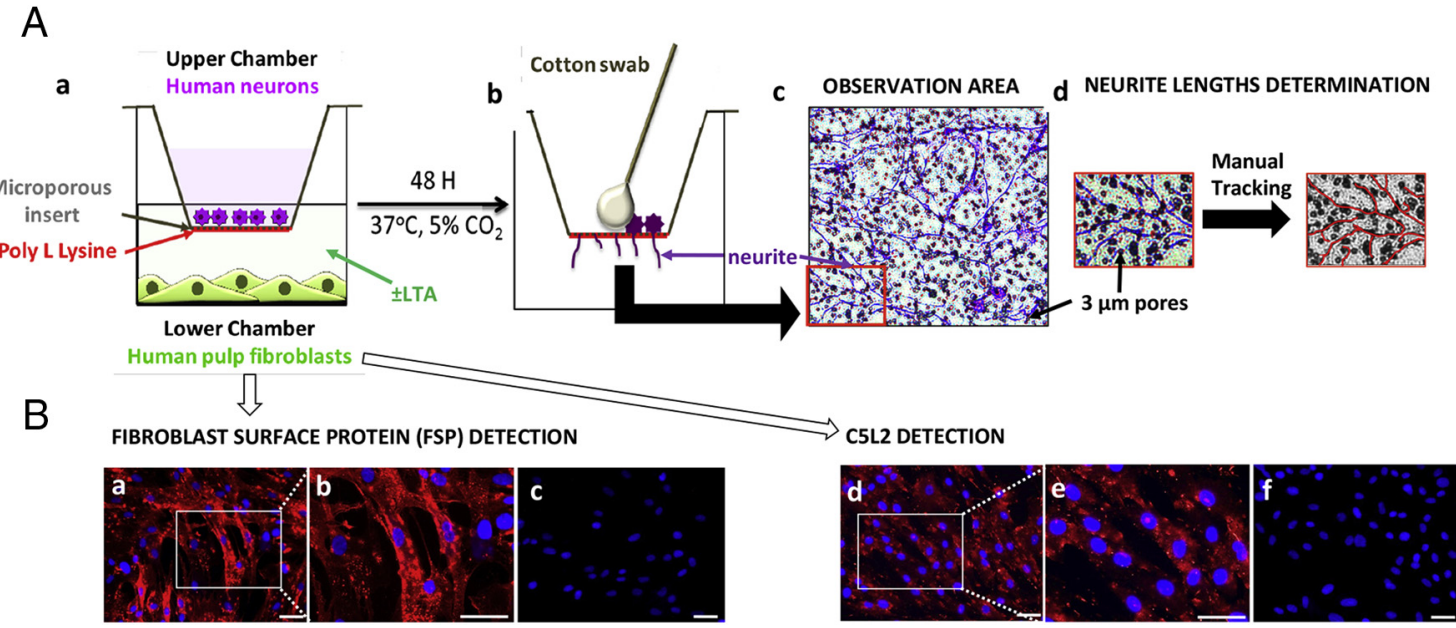

Figure 1. A) A schematic drawing of the neurite outgrowth protocol. (a) Neurite outgrowth was assayed in 24-well plates equipped with transwell inserts with a $3-\mu \mathrm{m}$ pore-size poly-L-lysine-coated membrane. Human neurons were seeded in the upper chamber, and human pulp fibroblasts silenced for $\mathrm{C} 5 \mathrm{~L} 2$ were incubated with or without LTA in the lower chamber. The neurite outgrowth was realized from the upper to the lower chamber through the porous insert. $(b)$ After a 48 -hour neurite extension period, neurons were fixed with cold methanol and incubated in a neurite stain solution, and neuron cell bodies were swabbed from the top inserts. $(c)$ Pictures of the lower surface of the porous membrane were realized under a light microscope. $(d)$ A reduced surface of the observation area was chosen to illustrate the determination of the neurite lengths by manual tracking. $(B)(a$ and $b$ ) Immunofluorescent staining was used to confirm the expression of FSP by human pulp cells used in this study. (c) No FSP labeling was detected in the negative controls. ( $d$ and $e$ ) Moreover, we confirmed by immunofluorescent staining that human pulp fibroblasts express the C5L2 receptor. (f) No C5L2 labeling was detected in the negative controls. Nuclei were counterstained with $4^{\prime}, 6$-diamidino2-phenylindole (blue). $b$ and $e$ are magnified from the box in $a$ and $d$, respectively. Scale bar $=50 \mu \mathrm{m}$. 
the lower surface of the membrane of each insert (Fig. 1Ac) was tracked in 5 random fields using Image 1.43 software (National Institutes of Health, Bethesda, MD), and the results were expressed as mm neurite/mm² (Fig. $1 A d)$.

\section{Statistical Analysis}

All experiments were repeated at least 3 times, and statistical significance was determined using the Student $t$ test to compare the different treatments and their respective controls. Data were expressed as means \pm standard deviation and considered significant at $P<.05$.

\section{Results \\ Isolated Human Pulp Fibroblasts in a Nerve Outgrowth Assay Chamber Express C512}

Previously, we used the Axon Investigation System device (SigmaAldrich), which allowed us to investigate the interaction between the 2 different cell types: pulp fibroblasts and neurons $(7,8)$. In this study, we established a simple and efficient coculture method to measure C5L2mediated nerve outgrowth. Human pulp fibroblasts were placed in the lower chamber, and cortical neurons were housed in the upper chamber (Fig. 1A). We first checked the cell viability in these chambers under normal and LTA stimulation. Because gram-positive bacteria constitute the predominant cariogenic bacteria (14), we decided to use LTA, which is a complex component of gram-positive bacteria cell walls, to simulate the presence of these bacteria in the pulp.

FSP and C5L2 expression was validated using anti-FSP/C5L2 immunofluorescence staining (Fig. $1 B$ ). FSP expression is restricted to the cytoplasm of the pulp fibroblasts (Fig. $1 B a$ and $B b$ ). C5L2 labeling is also strongly detected in these cells (Fig. $1 B d$ and $B e$ ). Highermagnification images combined with $4^{\prime}, 6$-diamidino-2-phenylindole staining show that all cells in the lower chamber express both FSP (Fig. $1 B b$ ) and C5L2 (Fig. 1Be). No FSP and C5L2 expression is detected in negative (no primary antibodies) control isotypes (Fig. $1 B c$ and $B f$ ).

\section{C5I2 siRNA-silenced Pulp Fibroblasts Express Significantly Less C5L2}

To identify the role of C5L2 in our nerve outgrowth assay kit, an siRNA-mediated gene silencing approach was used. The C5L2 siRNAsilencing efficiency was checked on pulp fibroblasts transfected either with control (Fig. $2 A-E$ ) or C5L2-siRNAs (Fig. $2 F-J$ ). Immunostaining with anti-C5L2 antibody showed that $\mathrm{C} 5 \mathrm{~L} 2$ was strongly expressed in all fibroblasts transfected with control siRNA (Fig. $2 B$ ). When the pulp fibroblasts were transfected with C5L2 siRNA, C5L2 expression was significantly decreased (Fig. 2G), confirming our successful gene silencing efficiency. Furthermore, real-time polymerase chain reaction analysis has been performed to confirm the efficiency of $\mathrm{C} 5 \mathrm{~L} 2$ silencing in pulp fibroblasts. The C5L2 messenger RNA expression was significantly decreased in the silencing pulp fibroblasts (Fig. $2 K$ ).

\section{C5L2 Inhibition Increased Neurite Outgrowth under LTA Stimulation}

Because C5L2 in LTA-treated human pulp fibroblasts seems to be implicated in the modulation of BDNF secretion (7), a neurite outgrowth assay was performed using human cortical neurons and pulp fibroblasts to identify the role of C5L2 in the nerve outgrowth process (Fig. 1A).
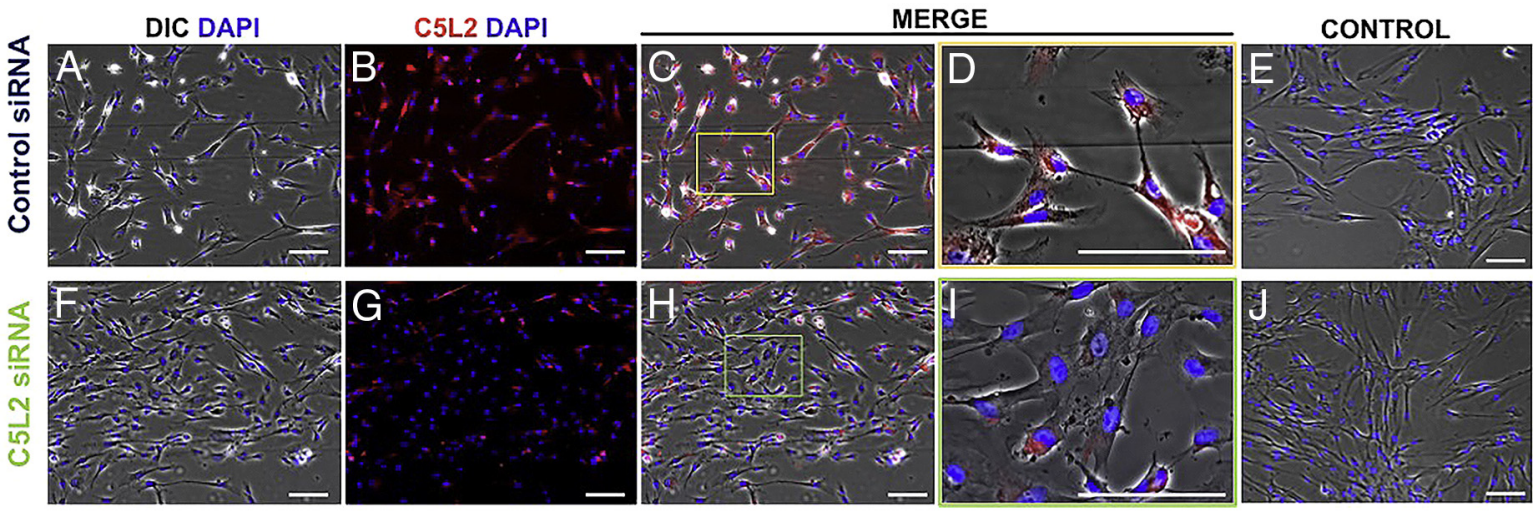

$\mathrm{K}$

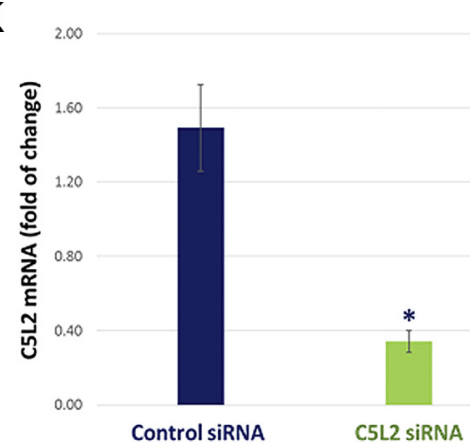

Figure 2. To confirm siRNA silencing efficiency, fluorescent staining was performed on pulp fibroblasts transfected with either $(A-E)$ control or $(F-J)$ C5L2 siRNAs. C5L2 was expressed in all fibroblasts transfected with $(B$ and $C)$ control siRNA and is clearly visible at $(D)$ a higher magnification. However, C5L2 expression was reduced in pulp fibroblasts transfected with $(G-I)$ C5L2 siRNA. ( $E$ and $J)$ No C5L2 labeling was detected in the negative controls. $D$ and $I$ are magnified views from the boxes in $C$ and $H$, respectively. Nuclei were counterstained with $4^{\prime}, 6$-diamidino-2-phenylindole $($ blue $)$. $(K)$ Real-time polymerase chain reaction analysis further confirms the efficiency of C5L2 silencing in pulp fibroblasts. DIC, differential interference contrast. Scale bar $=50 \mu \mathrm{m}$. 
Fewer neurite outgrowth was detected on the underside of the insert's membrane when pulp fibroblasts were transfected with control siRNA in the lower chamber (Fig. $3 A$ and $B$ ). The number of visualized neurites appeared to be increased in the LTA treatment group (Fig. $3 C$ and $D$ ). The number of neurites detected was increased when the pulp fibroblasts of the lower chamber were silenced with C5L2 siRNA (Fig. $3 E$ and $F$ ). Moreover, LTA stimulation of these C5L2-silenced fibroblasts significantly increased neurite outgrowth to the underside of the insert's membrane (Fig. $3 G$ and $H$ ).

We performed quantitative assessment of actual nerve growth (Fig. $1 A d)$. Consistent with previous publications $(7,8)$, neurite outgrowth was significantly higher in LTA stimulation than in the unstimulated condition (Fig. 4: blue bar untreated $=825.13 \pm 98.38 \mathrm{~mm} /$ $\mathrm{mm}^{2}$ vs blue bar LTA $=1411.99 \pm 146.66 \mathrm{~mm} / \mathrm{mm}^{2}$ ). This increase in neurite length was more significant when the pulp fibroblasts placed in the lower chamber were silenced for C5L2 (Fig. 4: green bar untreated $=1093.22 \pm 60.77 \mathrm{~mm} / \mathrm{mm}^{2}$ vs green bar $L T A=2206.66 \pm 258.03 \mathrm{~mm} / \mathrm{mm}^{2}$ ). Interestingly, we were able to confirm that $\mathrm{C5} 2 \mathrm{~L}$ silencing also significantly increased neurite outgrowth without LTA stimulation (Fig. 4: blue bar untreated vs green bar untreated), suggesting its capacity to regenerate injured nerves in the normal condition. Taken together, these data show that $\mathrm{C} 5 \mathrm{~L} 2$ inhibition drastically increased neurite outgrowth, constituting C5L2 as a negative regulator of neurite outgrowth under LTA stimulation.

\section{Discussion}

Our study revealed a novel role of the previously less explored $\mathrm{C} 5$ a receptor $\mathrm{C} 5 \mathrm{~L} 2$ in controlling nerve outgrowth by pulp fibroblasts under an LTA-induced carieslike inflammatory context, constituting C5L2 as a negative regulator of neurite outgrowth. Dental caries is one of the most common human infectious diseases (15). Its progression into dental pulp leads to multiple responses including inflammation, necrosis, and regeneration. Nerve fiber/ ending sprouting is observed in regenerating pulp $(16,17)$, and significant differences of nerve fiber innervation pattern and density were reported in carious teeth compared with healthy teeth, suggesting nerve regeneration's critical role(s) in the caries

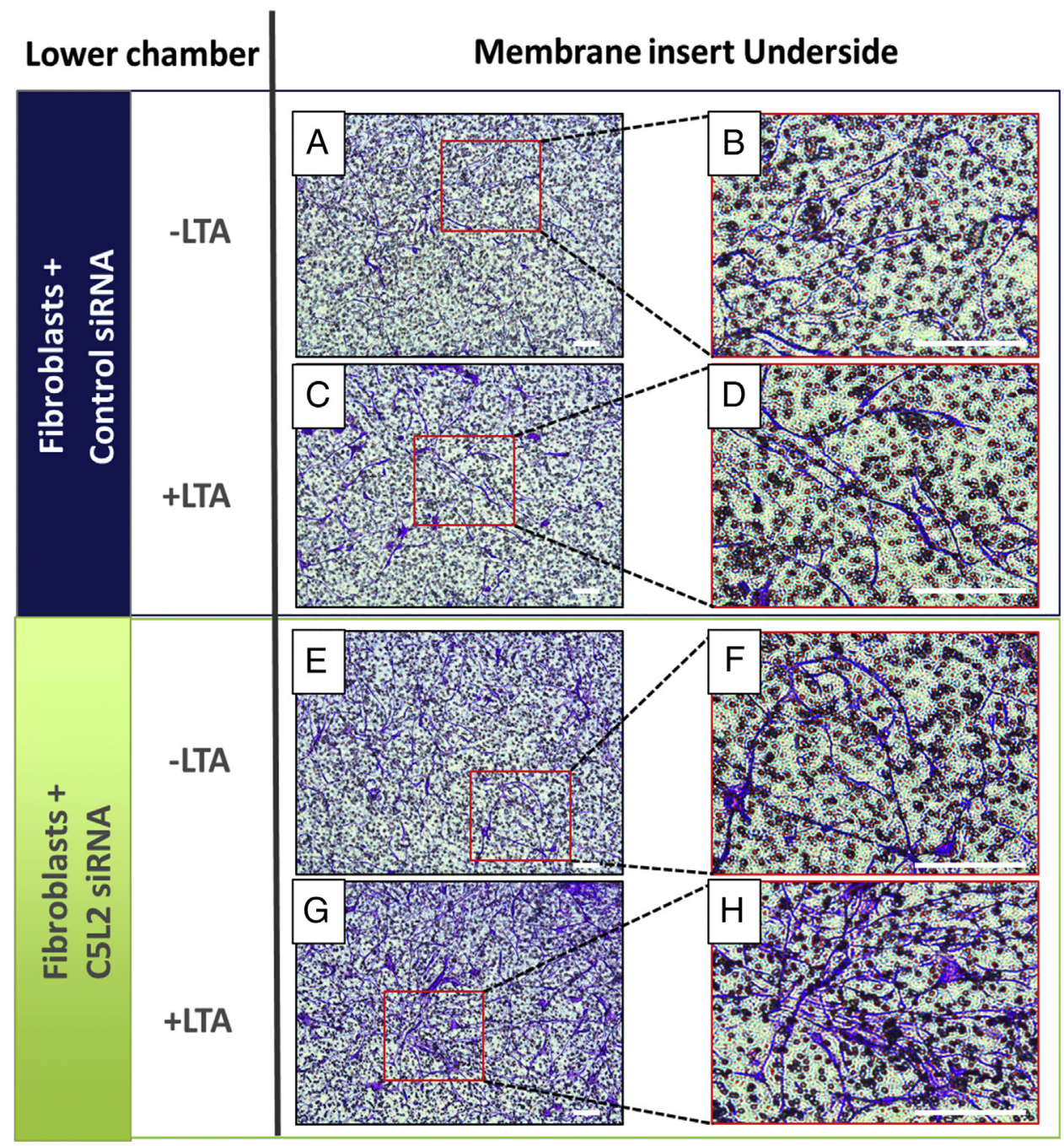

Figure 3. Representative images of neurite outgrowth on the lower surface of the porous membrane. $(A$ and $B$ ) Few neurites were observed when pulp fibroblasts transfected with control siRNA were plated in the lower chambers of the system. ( $C$ and $D$ ) The number of neurites detected seemed to be increased by the incubation of these fibroblasts with LTA. $(E$ and $F$ ) The number of neurites detected was increased when the pulp fibroblasts of the lower chamber were silenced for C5L2 expression. ( $G$ and $H$ ) Moreover, LTA stimulation of these C5L2-silenced fibroblasts drastically increased the number of neurites detected. $B, D, F$, and $H$ are magnified from the box in $A, C, E$, and $G$, respectively. Scale bars: $A-H=50 \mu \mathrm{m}$. 


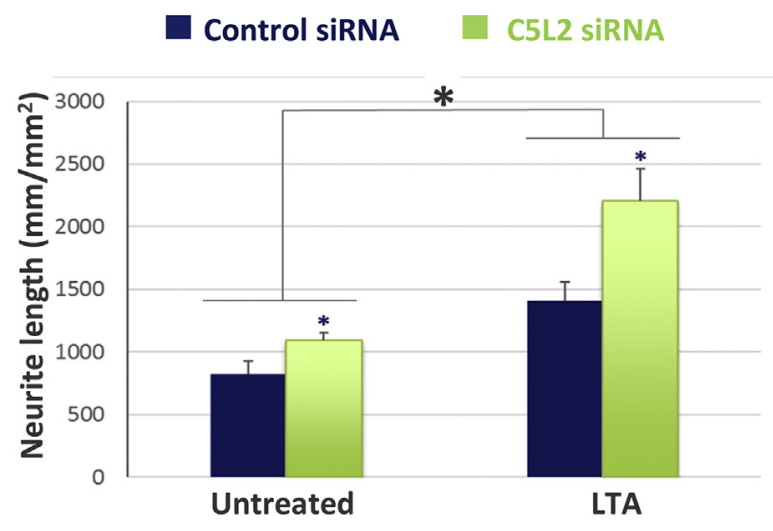

Figure 4. Neurite outgrowth experiments were shown in a histogram as the neurite length in $\mathrm{mm} / \mathrm{mm}^{2} \pm$ standard error of the mean. When pulp fibroblasts were stimulated with LTA, the length of the neurite outgrowth toward the lower chamber was significantly higher than in unstimulated conditions. This increase was significantly higher when the pulp fibroblasts plated in the lower chamber were silenced for C5L2 expression. Interestingly, we observed that $\mathrm{C} 5 \mathrm{~L} 2$ expression silencing also significantly increased neurite outgrowth even in the unstimulated condition. ${ }^{*} P<.05 . n=3$ per group.

process (18). Despite the nociceptive role of dental nerve cells, nerves may influence regeneration. Indeed, they affect regeneration by the induction of immune cell recruitment and vascular permeability enhancement (18-21). Evidently, a mutual interaction between the immune and nervous systems is necessary in the defense against bacterial invasion $(22,23)$.

Gram-positive bacteria constitute the predominant cariogenic bacteria (14). LTA from gram-positive Staphylococcus aureus was used to simulate the presence of these bacteria in the pulp. We are aware that LTA treatment from Staphylococcus aureus cannot mimic all facets of dental caries in vivo given the possible role of gram-negative bacteria with lipopolysaccharide, but it is generally accepted that LTA is a major component of oral pathogens in carious decays $(24,25)$. Indeed, our Brown and Brenn coloration staining confirmed a predominant part on carious tooth sections was gram-positive bacteria (12).

Despite earlier studies $(21,26,27)$ underscoring the relationship between innervation and wound healing in other tissues, there remain significant gaps in understanding innervation during pulp regeneration. The biological and molecular events orchestrating this process are still unknown. Pulp fibroblasts have been established as a source of regeneration signals in traumatic injury (28). However, their ability to secrete regeneration signals in response to caries has not been given much attention (6). Our previous study showed a critical role of C5aR, expressed by pulp fibroblasts, as a positive regulator in nerve regeneration of carious teeth (7). We have also shown that pulp fibroblasts coexpress both C5aR and C5L2 under LTA stimulation, demonstrating that C5a fixation on C5aR induced its phosphorylation and mediated local BDNF secretion. Additionally, silencing C5L2 increased BDNF secretion (12). Thus, our work provides a confirmation of these data by showing that C5L2 acts as a negative regulator of BDNF secretion by pulp fibroblasts and nerve outgrowth under carious injuries.

This was performed using a simplified Boyden chamber specifically adapted to investigate neuron-fibroblast interactions and nerve sprouting. This simple model can further be used to study the interactions between neurons and other cell types in pulp inflammation and regeneration processes. We used human cortical neurons in the neurite growth assay instead of human trigeminal neurons because we were not able to acquire human trigeminal neurons.
Different types of nerve endings have been known to possess different biochemical properties because they differ in functionality such that the cortical neurons receive multiple inputs from nearby neurons and interneurons, whereas the sensory neurons mostly contribute 1-way signal conduction. There may be specific interactions required between the trigeminal neuron fiber endings with pulp fibroblasts in the context of dental sensory innervation. However, our study confirms that pulp fibroblasts can interact with nerve fibers of cortical neurons, thus raising the possibility of using these cells in other peripheral nerve injury models.

The results from this study further reveal $\mathrm{C} 5 \mathrm{a} / \mathrm{C} 5 \mathrm{~L} 2$ as a key initial signal in dental pulp nerve sprouting under carious injuries by providing direct evidence of C5L2's critical role in pulp fibroblast implication in inducing significant neurite outgrowth toward the injured site. A new mechanism of the complement system and the novel receptor identified in this study may provide a useful future therapeutic tool in targeting the pulp fibroblasts in the dentin-pulp regeneration process.

\section{Acknowledgments}

Supported by start-up funds from the University of Illinois at Chicago College of Dentistry (S.H.C.).

The authors deny any conflicts of interest related to this study.

\section{References}

1. Byers MR, Taylor PE. Effect of sensory denervation on the response of rat molar pulp to exposure injury. J Dent Res 1992;72:613-8.

2. Fristad I, Heyeraas KJ, Kvinnsland IH, et al. Recruitment of immunocompetent cells after dentinal injuries in innervated and denervated young rat molars: an immunohistochemical study. J Histochem Cytochem 1995:43:871-9.

3. Yamashiro T, Fujiyama K, Fukunaga T, et al. Epithelial rests of Malassez express immunoreactivity of TrkA and its distribution is regulated by sensory nerve innervation. J Histochem Cytochem 2000;48:979-84.

4. Fujiyama K, Yamashiro T, Fukunaga T, et al. Denervation resulting in dento-alveolar ankylosis associated with decreased Malassez epithelium. J Dent Res 2004;83: $625-9$.

5. Park KD, Sung JH, Bae YC, et al. Effects on osteoclast in periodontal ligament space by denerveation of inferior alveolar nerve in young and adult rats. Korean J Orthod 2004;34:506-13.

6. Jeanneau C, Lundy FT, El Karim IA, et al. Potential therapeutic strategy of targeting pulp fibroblasts in dentin-pulp regeneration. J Endod 2017;43:S17-24.

7. Chmilewsky F, About I, Chung SH. Pulp fibroblasts control nerve regeneration through complement activation. J Dental Res 2016;95:913-22.

8. Chmilewsky F, Ayaz W, Appiah J, et al. Nerve growth factor secretion in pulp fibroblasts is modulated by complement c5a receptor and implied in neurite outgrowth. Sci Rep 2016;6:31799.

9. Ohno M, Hirata T, Enomoto M, et al. A putative chemoattractant receptor, C5L2, is expressed in granulocyte and immature dendritic cells, but not in mature dendritic cells. Mol Immunol 2000;37:407-12.

10. Li R, Coulthard LG, Wu MC, et al. C5L2: a controversial receptor of complement anaphylatoxin, C5a. FASEB J 2013;27:855-64.

11. Bamberg CE, Mackay CR, Lee H, et al. The C5a receptor (C5aR) C5L2 is a modulator of C5aR-mediated signal transduction. J Biol Chem 2010;285:7633-44.

12. Chmilewsky F, About I, Chung SH. C5L2 receptor represses BDNF secretion in LTAstimulated pulp fibroblasts. J Dent Res 2017;96:92-9.

13. About I, Bottero MJ, de Denato P, et al. Human dentin production in vitro. Exp Cell Res 2000;258:33-41.

14. Martin FE, Nadkarni MA, Jacques NA, et al. Quantitative microbiological study of human carious dentine by culture and real-time PCR: association of anaerobes with histopathological changes in chronic pulpitis. J Clin Microbiol 2002;40:1698-704.

15. Islam B, Khan SN, Khan AU. Dental caries: from infection to prevention. Med Sci Monit 2007; 13:196-203.

16. Taylor PE, Byer MR, Redd PE. Sprouting of CGRP nerve fibers in response to dentin injury in rat molars. Brain Res 1988;461:371-6.

17. Arai H. Neurohistological study on responses of nerve fibers to pulpitis in human teeth. Jap J Conserv Dent 1991;34:1631-46.

18. Couve E, Osorio R, Schmachtenberg 0 . Reactionary dentinogenesis and neuroimmune response in dental caries. J Dent Res 2014;93:788-93. 


\section{Basic Research-Biology}

19. Byers MR, Nähri MV. Dental injury models: experimental tools for understanding neuroinflammatory interactions and polymodal nociceptor functions. Crit Rev Oral Biol Med 1999;10:4-39.

20. About I. Dentin regeneration in vitro the pivotal role of supportive cells. Adv Dent Res 2011;23:320-4.

21. Hanoun M, Maryanovich M, Arnal-Estapé A, et al. Neural regulation of hematopoiesis, inflammation, and cancer. Neuron 2015;86:360-73.

22. Steinman L. Elaborate interactions between the immune and nervous systems. Nat Immunol 2004;5:575-81.

23. Jung WC, Levesque JP, Ruitenberg MJ. It takes nerve to fight back: the significance of neural innervation of the bone marrow and spleen for immune function. Semin Cell Dev Biol 2017;61:60-70.
24. Hahn CL, Best AM, Tew JG. Cytokine induction by Streptococcus mutans and pulpal pathogenesis. Infect Immun 2000;68:6785-9.

25. Hong SW, Seo DG, Baik JE, et al. Differential profiles of salivary proteins with affinity to Streptococcus mutans lipoteichoic acid in caries-free and caries-positive human subjects. Mol Oral Microbiol 2014;29:208-18.

26. Stelnicki EJ, Doolabh V, Lee S, et al. Nerve dependency in scarless fetal wound healing. Plast Reconstr Surg 2000;105:140-7.

27. Muangman P, Muffley LA, Anthony JP, et al. Nerve growth factor accelerates wound healing in diabetic mice. Wound Repair Regen 2004;12:44-52.

28. Tran-Hung L, Laurent P, Camps J, et al. Quantification of angiogenic growth factors released by human dental cells after injury. Arch Oral Biol 2008;53: 9-13. 